\title{
Harms unknown: health uncertainties cast doubt on the role of unconventional gas in Australia's energy future
}

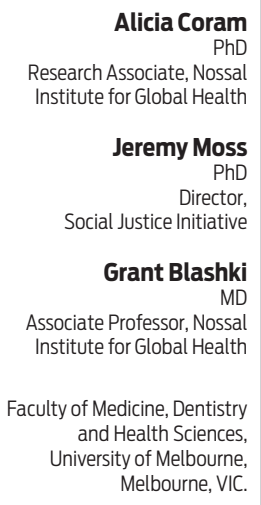

doi: 10.5694/mjal3.11023
A ustralia has significant reserves of unconventional gas, with combined estimated reserves of coal seam, shale and tight gas amounting to over three and a half times those of conventional gas. ${ }^{1}$ The industry is undergoing rapid growth as a result of advances in gas extraction techniques - most notably the widespread adoption of hydraulic fracturing (commonly known as fracking), which involves injecting large quantities of water, chemicals and proppants (materials like sand intended to keep fractures open) into gas reservoirs to open fractures and allow the gas to flow more readily. While coal seam gas (CSG) has been the focus of much public debate in Australia, it is the nascent shale gas industry that is likely to be responsible for the biggest expansion of hydraulic fracturing in the coming decades.

The promise of reliable and affordable energy, the potential windfall from exports, and claims that it is less damaging to the climate than coal have become major selling points of unconventional gas for its proponents. However, the industry has been beset by controversy over its potential negative health, social and environmental impacts.

Fears over the potential health implications of hydraulic fracturing led over 100 medical practitioners to request the Obama administration to halt the construction of new liquefied natural gas (LNG) terminals on the basis that "[t]here is a growing body of evidence that unconventional natural gas extraction from shale ... may be associated with adverse health risks through exposure to polluted air, water, and soil" ${ }^{2}$ There are also environmental, social and psychological factors that have more indirect effects on health, and important social justice implications arising from the distribution of health burdens.

While there is a dearth of conclusive evidence about the health and environmental effects of fracturing, there is an emerging body of evidence on the areas of greatest potential risk and uncertainty in regards to water, air and social pathways. When taken into consideration along with concerns about the level of fugitive emissions and the potential effect on the development of renewable energy, these health concerns make unconventional gas a doubtful saviour for Australia's energy needs.

\section{Wastewater is a greater hazard than fracturing fluids}

The risk of fracturing chemicals directly contaminating water used for drinking or irrigation has been one of the

\section{Summary}

- There is a push to increase production of unconventional gas in Australia, which would intensify the use of the controversial technique of hydraulic fracturing.

- The uncertainties surrounding the health implications of unconventional gas, when considered together with doubts surrounding its greenhouse gas profile and cost, weigh heavily against proceeding with proposed future developments.

- The health and environmental impacts of hydraulic fracturing have been the source of widespread public concern. A review of available literature shows a considerable degree of uncertainty, but an emerging consensus about the main risks.

- Gas is often claimed to be a less climate-damaging alternative to coal; however, this is called into question by the fugitive emissions produced by unconventional gas extraction and the consequences of its export.

- While the health effects associated with fracturing chemicals have attracted considerable public attention, risks posed by wastewater, community disruption and the interaction between exposures are also of concern.

- The health burdens of unconventional gas are likely to fall disproportionately on rural communities, the young and the elderly.

- While the health and environmental risks and benefits must be compared with other energy choices, coal provides a poor benchmark.

main sources of public concern. While the risk of well casing failure, spills and other accidents cannot be dismissed, ${ }^{3,4}$ these can be mitigated (though not removed entirely) by proper regulation and the move towards "safer" fracturing fluids. However, although any exposure would likely be to heavily diluted chemicals, the toxicological effects of some chemicals in their dilute form are not well understood. 5,6 In particular, chemicals affecting the endocrine system such as ethoxylated 4-nonylphenol, which has been used in Australian operations ${ }^{6}$ - can affect humans at extremely low quantities. ${ }^{7}$

The fate of stranded fracturing fluids (those remaining underground) has also not been well established, and there is a significant failure rate for abandoned wells in the United States, leading to materials leaking into the surrounding areas. ${ }^{8}$ Additionally, while the minor seismic activity caused by fracturing is unlikely to result in earthquakes of a magnitude that can be felt, it introduces a further risk of damage to well casings.

However it is wastewater, which contains naturally occurring contaminants that are difficult and costly to 
remove (as well as fracturing and drilling fluids), that poses a greater human and environmental health risk. ${ }^{4,8}$ There are many documented and anecdotal cases of spills, failures of holding dams, and the accidental and planned release of contaminated wastewater in Australia and the US. ${ }^{9-11}$ Natural contaminants present in wastewater can include heavy metals and radioactive materials, which have serious and well known health effects. ${ }^{8}$ Uranium and heavy metals have been shown to be mobilised by fracturing and drilling chemicals. ${ }^{12}$

\section{Unconventional gas developments create air pollution}

One of the clearest health benefits of gas over coal is the fact that it is responsible for significantly less damaging particulate matter (PM) than coal. ${ }^{13}$ However, unconventional gas extraction is responsible for air pollution from diesel fumes from infrastructure development and stationary equipment, gas processing, venting and flaring. Fugitive methane emissions can catalyse development of ground level ozone and combine with PM to form smog, both of which contribute to respiratory disease, among other health effects, and damage to crops - gasfield haze is a well known effect in the US, with such pollution capable of travelling substantial distances. ${ }^{14}$ Shale gas extraction can also involve the flaring or venting of "associated" gases, which can become hazardous air pollutants. ${ }^{15}$

The cumulative risks from these sources are difficult to estimate, however one study calculated the cumulative cancer risks for residents of Battlement Mesa, Colorado, to be " 6 in a million for residents $>1 / 2$ mile from wells and 10 in a million for residents $\leqslant 1 / 2$ mile from wells", also noting other symptoms reported by residents "consistent with known health effects of many of the hydrocarbons evaluated". ${ }^{16}$

It is likely that the distance of most Australian operations from densely populated areas at present makes the health impacts of air pollution less pronounced than in the US, although this may change as the industry fights against current setback restrictions. Although not conclusive, findings from an investigation of "downwinder's syndrome" in Queensland suggested no direct link to air pollution, ${ }^{17}$ and pollution can also be reduced by improvements to equipment. However it is becoming apparent that any level of such air pollutants can have health implications at a population level. ${ }^{13}$ Further, given the opportunity to move to far less polluting alternatives such as renewable energy, the reduction of PM compared with coal is not enough to recommend further gas developments.

Moreover, air pollution remains a potentially serious health issue for workers. Although the nature of risks to workers is unclear, potential exposures include toxic materials and chemicals, airborne silica from sand used as a proppant, and radon. A significant number of air samples collected in the US exceeded the recommended exposure limits for airborne silica, with one report claiming the potential of developing silicosis to be a significant known health hazard to workers involved in hydraulic fracturing. ${ }^{18}$

\section{Social impacts exacerbate other health effects}

Gas developments can have numerous and considerable social and psychological effects, which may exacerbate more direct health risks. Although there are potential benefits to communities, and effects are likely to be mixed, ${ }^{14}$ a study of the impacts of mining and CSG operations on the mental health of landholders in Queensland concluded that these operations placed rural communities "under sustained stress", with study participants perceiving that these operations "significantly impacted or exacerbated issues such as the health, social fabric and economy of the community", and the authors noting that local health services faced "unsustainable pressure" ${ }^{19}$

Unconventional gas developments in Australia also make use of fly-in, fly-out and drive-in, drive-out workforces. While these arrangements have some benefits, they have come under scrutiny for their negative influence on community cohesion, increasing the cost of living, and their association with high levels of alcohol and drug use, mental health issues and violence (although these latter are also more generally associated with the demographic of young men who make up most of these workers). ${ }^{20}$

\section{Social justice implications require more attention}

Inequity can be an indirect cause of ill health, and the development of unconventional gas resources threatens to distribute health burdens in an unfair way. Most of the potential health hazards are likely to be felt by groups such as the elderly, children and the poor because of their vulnerability to the hazards involved, those living in rural, agricultural and Indigenous communities because of the location of operations, and future generations - the same groups liable to bear significant costs of climate change while the financial benefits will accrue to the predominantly foreign owners of the resources.

Australia must also take responsibility for the moral implications of our role as one of the world's largest exporters of gas, with exports expected to reach nearly $70 \%$ of gas production by 2035 . The emissions from the combustion of exported gas are not included in our national inventory; however it is plausible that countries have a prima facie responsibility for at least part of the harms caused by their exported emissions. According to the International Energy Agency, "Only one third of the carbon contained in proven reserves of fossil fuels can be released into the atmosphere by 2050 if the world is to achieve its under $2{ }^{\circ} \mathrm{C}$ goal" ${ }^{21}$

It is clear that, insofar as we need to extract and use fossil fuel resources, this needs to occur in a controlled and fair way, but there are currently no such constraints on our development of new sources of gas.

\section{The question of fugitive emissions}

A further health issue raised by any proposed energy source is its contribution to climate change, which has the potential to reverse gains in global health, for example by exacerbating illnesses and causing deaths through undernutrition, 
extreme weather conditions and disease. ${ }^{22}$ The combustion of gas produces about $40 \%$ of the greenhouse gas (GHG) emissions of coal, which has been offered as a reason to support the industry's expansion, either as a "stepping stone" towards renewables or as an end point in itself. However, this proposed benefit is called into serious question by the level of fugitive emissions (emissions that are not captured for use) produced by its extraction and transport. There is considerable disagreement about the extent of these emissions, with estimates ranging from $0.1 \%$ to $9 \%$ of gas produced (with current US Environmental Protection Agency estimations at about 2.4\%). ${ }^{23-26}$ Notably, there are as yet no reliable figures for Australian operations, ${ }^{27}$ and regardless of how it compares to coal, unconventional gas is responsible for large quantities of GHG emissions in absolute terms.

Unconventional gas is predominantly methane, which is estimated to have a global warming potential 25 times greater than carbon dioxide over a 100-year period, and 72 times greater over a 20 -year period. ${ }^{28}$ The nature of climate change and the possibility of "tipping points" in the short term make it important to consider this perspective, with several reports estimating fugitive emissions from unconventional gas to be of a level (between 2\% and 3.2\% of production) that would likely undermine its climate benefits compared with coal in this time frame. ${ }^{29,30}$ The effects of climate change, such as increased floods and drought, can be expected to exacerbate many risks, and are also likely to disproportionately affect vulnerable groups. This highlights the importance of considering the shortterm global warming potential of methane and the social justice implications of energy choices.

Increased gas production may also displace emerging renewables markets in export countries and impair the growth of the renewables sector in Australia. In addition, the technology used for generating energy from exported LNG cannot be assumed to be of comparable efficiency to that deployed in Australia. ${ }^{31}$

\section{Implications of the health impacts of unconventional gas}

The current evidence does not provide a clear picture of the health implications accompanying the proposed expansion of Australia's unconventional gas industry. In some cases, this is because of gaps in our knowledge that could be rectified, while other risks are inherently uncertain because they involve complex systems and interacting health pathways.

It is important to note that the absence of concrete evidence of harm does not equate to evidence of its absence. The uncertainty over the health implications of unconventional gas is greater than that surrounding any other energy choice, and suggests that adopting an attitude of precaution - such as that employed with the introduction of a new drug - is justified on the basis of health risks alone.

However, as with decision making in a clinical setting, appeals to precaution need to take place in a broader assessment of risks and benefits. In the case of unconventional gas, this includes its implications for climate change, which — as argued above - also indicate its unsuitability. Further, while it is commonplace to compare gas with coal, coal is known to inflict serious damage on human and environmental health, ${ }^{32}$ making it a poor benchmark and obscuring unfavourable comparisons with renewable energy choices.

It is clear that Australia must quickly move beyond its reliance on coal for health and environmental reasons. However, when taking into consideration the uncertainties over health risks, the unfavourable comparisons with other energy options, the climate risks associated with fugitive emissions, the moral obligations Australia faces as a gas exporter, the potential displacement of renewables and doubts raised over the claim that gas will prove to be a cheap energy option, ${ }^{33}$ the scale is firmly tipped against the further development of unconventional gas.

Acknowledgements: We would like to acknowledge support by a grant from Kindness House and an Australian Research Council Discovery Grant to Jeremy Moss (Egalitarian Responses to Climate Change).

Competing interests: This work was made possible by grants from the Social Justice Initiative, the Melbourne Energy Institute and the Melbourne Sustainable Society Institute at the University of Melbourne, and Kindness House. Grant Blashki is a former board member of the Australian Conservation Foundation and chairs the Environmental Working Party of the World Organisation of Family Doctors.

Provenance: Not commissioned; externally peer reviewed.

1 Geoscience Australia and the Bureau of Resources and Energy Economics. Australian gas resource assessment 2012. Canberra: Commonwealth of Australia, 2012. http://www.bree.gov.au/documents/publications/other/ gasResourceAssessment.pdf (accessed Nov 2013).

2 Physicians Scientists and Engineers for Healthy Energy. More than 100 leading medical, scientific experts urge White House to halt rush to expanded shale gas fracking for export purposes [media release]. $31 \mathrm{Dec}$ 2012. http://www.psehealthyenergy.org/data/LNG_PressReleasePDF.pdf (accessed Oct 2013).

3 Broderick J, Anderson K, Wood R, et al. Shale gas: an updated assessment of environmental and climate change impacts. A report commissioned by The Co-operative and undertaken by researchers at the Tyndall Centre, University of Manchester. Manchester: Tyndall Centre for Climate Change Research, 2011. http://www.tyndall.ac.uk/sites/default/files/coop_shale_ gas_report_update_v3.10.pdf (accessed Nov 2013).

4 Rozell DJ, Reaven SJ. Water pollution risk associated with natural gas extraction from the Marcellus Shale. Risk Anal 2012; 32: 1382-1393.

5 Colborn T, Kwiatkowski C, Schultz K, Bachran M. Natural gas operations from a public health perspective. Hum Ecol Risk Assess 2011; 17: 1039-1056. doi: 10.1080/10807039.2011.605662.

6 Lloyd-Smith M, Senjen R. Hydraulic fracturing in coal seam gas mining: the risks to our health, communities, environment and climate. Bangalow, NSW: National Toxics Network, 2011. http://ntn.org.au/wp/wp-content/ uploads/2012/04/NTN-CSG-Report-Sep-2011.pdf (accessed Oct 2013).

7 Vandenberg LN, Colborn T, Hayes TB, et al. Hormones and endocrinedisrupting chemicals: low-dose effects and nonmonotonic dose responses. Endocr Rev 2012; 33: 378-455.

8 Bishop RE. Fracking: chemical and biological risk assessment for natural gas extraction. Centre for Research on Globalization, 2011. http://www. globalresearch.ca/fracking-chemical-and- biological-risk-assessment-fornatural-gas-extraction/22940 (accessed Oct 2013).

9 Lechtenböhmer S, Altmann M, Capito S, et al. Impacts of shale gas and shale oil extraction on the environment and human health. European Parliament, Policy Department A: Economic and Scientific Policy, 2011. http://www.europarl.europa.eu/RegData/etudes/etudes/ join/2011/464425/IPOL-ENVI_ET(2011)464425_EN.pdf (accessed Nov 2013).

10 Doctors for the Environment. Submission to the Rural Affairs and Transport References Committee Inquiry into management of the Murray Darling Basin - impact of mining coal seam gas. 27 Jun 2011. http://dea.org.au/ images/uploads/submissions/MDB_CSG_Senate_submission_June_2011. pdf (accessed Nov 2013).

11 Bamberger M, Oswald RE. Impacts of gas drilling on human and animal health. New Solut 2012; 22: 51-77.

12 Bank TL. Fluid rock interactions associated with hydraulic fracturing and natural gas development. Global Water Magazine [internet] 2011; 27 Jan. http://globalwater.jhu.edu/magazine/article/fluid_rock_interactions_ associated_with_hydraulic_fracturing_and_natural_ga (accessed Nov 2013).

13 Rabl A, Spadaro JV. Public health impact of air pollution and implications for the energy system. Annu Rev Energy Env 2000; 25: 601-627. doi: 10.1146/ annurev.energy.25.1.601. 
14 Witter R, Stinson K, Sackett H, et al. Potential exposure-related human health effects of oil and gas development: a white paper. Aurora, Colo: Colorado School of Public Health, 2008. http://docs.nrdc.org/health/files/ hea_08091702a.pdf (accessed Nov 2013).

15 Colborn T, Schultz K, Herrick L, Kwiatkowski C. An exploratory study of air quality near natural gas operations. Hum Ecol Risk Assess 2014; 1: 86-105. doi: 10.1080/10807039.2012.749447.

16 McKenzie LM, Witter RZ, Newman LS, Aldgate JL. Human health risk assessment of air emissions from development of unconventional natural gas resources. Sci Total Environ 2012; 424: 79-87.

17 Queensland Health. Coal seam gas in the Tara region: summary risk assessment of health complaints and environmental monitoring data. Queensland Government, 2013. http://www.health.qld.gov.au/ publications/csg/documents/report.pdf (accessed Nov 2013).

18 Esswein E, Kiefer M, Snawder J, Breitenstein M. Work exposure to crystalline silica during hydraulic fracturing. NIOSH Science Blog [internet] 2012; 23 May. http://blogs.cdc.gov/niosh-science-blog/2012/05/23/silica-fracking (accessed Nov 2013).

19 Hossain D, Gorman D, Chapelle B, et al. Impact of the mining industry on the mental health of landholders and rural communities in southwest Queensland. Australas Psychiatry 2013; 21: 32-37.

20 House of Representatives Standing Committee on Regional Australia. Cancer of the bush or salvation for our cities? Fly-in, fly-out and drivein, drive-out workforce practices in regional Australia. Canberra: Commonwealth of Australia, 2013. http://www.aph.gov.au/parliamentary business/committees/house_of_representatives_committees?url=ra/ fifodido/report.htm (accessed Nov 2013).

21 International Energy Agency. World energy outlook 2012. Paris: IEA, 2012.

22 Costello A, Abbas M, Allen A, et al. Managing the health effects of climate change: Lancet and University College London Institute for Global Health Commission. Lancet 2009; 373: 1693-1733.

23 Jiang M, Griffin WM, Hendrickson C, et al. Life cycle greenhouse gas emissions of Marcellus shale gas. Environ Res Lett 2011; 6: 034014. http:// iopscience.iop.org/1748-9326/6/3/034014/fulltext (accessed Nov 2013).
24 Howarth RW, Santoro R, Ingraffea A. Methane and the greenhousegas footprint of natural gas from shale formations. Climatic Change 2011; 106: 679-690. http://link.springer.com/content/ pdf/10.1007\%2Fs10584-011-0061-5.pdf (accessed Nov 2013).

25 Pétron G, Frost G, Miller BR, et al. Hydrocarbon emissions characterization in the Colorado Front Range: a pilot study. J Geophys Res 2012; 117. doi: 10.1029/2011JD016360.

26 Santos. Attachment K: greenhouse gas emissions. Gladstone Liquid Natural Gas project supplementary environmental impact statement. Santos GLNG, 2009. http://www.santosglng.com/media/pdf1624/AttachmentK_ Greenhouse_Gas_Emissions.pdf (accessed Nov 2013).

27 Day S, Connell L, Etheridge D, et al. Fugitive greenhouse gas emissions from coal seam gas production in Australia. Canberra: CSIRO, 2012. http:// www.csiro.au/ /media/CSIROau/Outcomes/Energy/CSG\%20fugitive\%20 emissions\%20report\%20set/CSG\%20Fugitive\%20Emissions\%20Report_ Final.ashx (accessed Nov 2013).

28 Intergovernmental Panel on Climate Change. IPCC fourth assessment report: climate change 2007. Geneva: IPCC, 2007.

29 Alvarez RA, Pacala SW, Winebrake JJ, et al. Greater focus needed on methane leakage from natural gas infrastructure. Proc Natl Acad Sci U S A 2012; 109: 6435-6440.

30 Wigley TML. Coal to gas: the influence of methane leakage. Climatic Change 2011; 108: 601-608. http://link.springer.com/content/ pdf/10.1007\%2Fs10584-011-0217-3.pdf (accessed Nov 2013).

31 Hardisty PE, Clark TS, Hynes RG. Life cycle greenhouse gas emissions from electricity generation: a comparative analysis of Australian energy sources. Energies 2012; 5: 872-897. doi: 10.3390/en5040872.

32 Castleden WM, Shearman D, Crisp G, Finch P. The mining and burning of coal: effects on health and the environment. Med J Aust 2011; 195: 333-335.

33 Grudnoff M. More coal seam gas means higher, not lower, prices. The Drum [internet] 2013; 8 Jul. http://www.abc.net.au/unleashed/4805342.html (accessed Oct 2013). 